\title{
Preeclamptic Plasma Induces Transcription Modifications Involving the AP-1 Transcriptional Regulator JDP2 in Endothelial Cells
}

\author{
Rosamaria Calicchio, ${ }^{*}$ Christophe Buffat, ${ }^{\dagger}$ Jacques R. Mathieu, ${ }^{*}$ Nour Ben Salem, ${ }^{\star}$ Celine Mehats, ${ }^{*}$ Sébastien Jacques, ${ }^{*}$ \\ Alexandre Hertig, ${ }^{\S}$ Nadia Berkane, ${ }^{\S}$ Julie Grevoul-Fresquet, ${ }^{\llbracket}$ Umberto Simeoni, ${ }^{\dagger}$ Carole Peyssonnaux, ${ }^{*}$ Julie Gavard, ${ }^{*}$ \\ Daniel Vaiman, ${ }^{*}$ and Francisco Miralles*
}

\begin{abstract}
From the Institut National de la Sante et la Recherche Medicale U1016-Centre National de la Recherche Scientifique UMR8104, * Université Paris Descartes, Institut Cochin, Paris, France; the Molecular Biology Laboratory, ${ }^{\dagger}$ Genetics and Endocrine Oncology, Hôpital de la Conception-Assistance PubliqueHopitaux de Marseille, Marseille, France; the Biochemistry Laboratory, ${ }^{\ddagger}$ Centre Hospitalier Universitaire Farhat Hached, Sousse, Tunisia; the Department of Obstetrics and Gynecology, Reproductive Medicine, ${ }^{\S}$ Hôpital Tenon, Paris, France; and the Gynecology and Obstetrics Service, ${ }^{\Uparrow}$ AP-HP Hôpital Bicêtre, Le Kremlin-Bicêtre, France
\end{abstract}

CME Accreditation Statement: This activity ("ASIP 2013 AJP CME Program in Pathogenesis") has been planned and implemented in accordance with the Essential Areas and policies of the Accreditation Council for Continuing Medical Education (ACCME) through the joint sponsorship of the American Society for Clinical Pathology (ASCP) and the American Society for Investigative Pathology (ASIP). ASCP is accredited by the ACCME to provide continuing medical education for physicians.

The ASCP designates this journal-based CME activity (“ASIP 2013 AJP CME Program in Pathogenesis") for a maximum of 48 AMA PRA Category 1 Credit(s) ${ }^{\mathrm{TM}}$. Physicians should only claim credit commensurate with the extent of their participation in the activity.

CME Disclosures: The authors of this article and the planning committee members and staff have no relevant financial relationships with commercial interests to disclose.

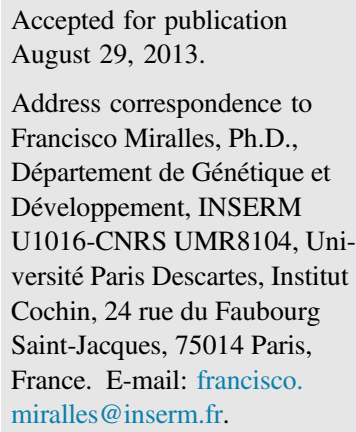

\begin{abstract}
Preeclampsia is a pregnancy disorder characterized by hypertension and proteinuria. In preeclampsia, the placenta releases factors into the maternal circulation that cause a systemic endothelial dysfunction. Herein, we investigated the effects of plasma from women with preeclamptic and normal pregnancies on the transcriptome of an immortalized human umbilical vein endothelial cell line. The cells were exposed for 24 hours to preeclamptic or normal pregnancy plasma and their transcriptome was analyzed using Agilent microarrays. A total of 116 genes were found differentially expressed: 71 were up-regulated and 45 were down-regulated. In silico analysis revealed significant consistency and identified four functional categories of genes: mitosis and cell cycle progression, anti-apoptotic, fatty acid biosynthesis, and endoplasmic reticulum stress effectors. Moreover, several genes involved in vasoregulation and endothelial homeostasis showed modified expression, including EDN1, APLN, NOX4, and CBS. Promoter analysis detected, among the up-regulated genes, a significant overrepresentation of genes containing activation protein-1 regulatory sites. This correlated with down-regulation of JDP2, a gene encoding a repressor of activation protein-1. The role of JDP2 in the regulation of a subset of genes in the human umbilical vein endothelial cells was confirmed by siRNA inhibition. We characterized transcriptional changes induced by preeclamptic plasma on human umbilical vein endothelial cells, and identified, for the first time to our knowledge, JDP2 as a regulator of a subset of genes modified by preeclamptic plasma. (Am J Pathol 2013, 183: 1993-2006; http://dx.doi.org/ 10.1016/j.ajpath.2013.08.020)
\end{abstract}

Preeclampsia is a pregnancy complication affecting approximately $5 \%$ to $8 \%$ of pregnancies and is capable of causing both maternal and fetal morbidity and mortality. ${ }^{1}$ The maternal syndrome develops after 20 weeks of gestational age
Supported by the Centre National de la Recherche Scientifique and Institut National de la Sante et la Recherche Medicale. R.C. is a recipient of a fellowship from the French Research Ministry (Paris XI University). 
and is characterized by elevated blood pressure $(>140 \mathrm{~mm}$ $\mathrm{Hg} / 90 \mathrm{~mm} \mathrm{Hg}$ ), proteinuria (>300 mg/24 hours), systemic endothelial cell (EC) dysfunction, and inflammation. Defective placentation is thought to be at the root of the disease. In the developing preeclamptic placenta, the normal process of trophoblast invasion and remodeling of the uterine maternal spiral arteries is impaired. This default leads to reduced placental perfusion, oxidative stress, and inflammation, with subsequent release of placental factors and debris into the maternal circulation. These factors are supposed to cause a widespread EC activation leading to the multisystem dysfunction characteristic of preeclampsia. ${ }^{2}$

Maternal endothelial dysfunction in preeclampsia is revealed by structural modifications of the ECs of the kidney glomeruli and by functional modifications, including changes in the balance of coagulant and anticoagulant factors and increased circulating concentrations of von Willebrand factor, endothelin-1 (ET-1), soluble adhesion molecules, and cytokines. Moreover, increased levels of the anti-angiogenic factors, soluble fms-like tyrosine kinase-1 (sFLt1) and soluble endoglin, presumably released by the placenta, are found in the plasma of preeclamptic women. Therefore, endothelial dysfunction can, by itself, explain many maternal symptoms of preeclampsia. EC dysfunction will lead to hypertension due to vasoconstriction and proteinuria due to glomerular damage, and would be the cause of systemic inflammation and edema due to increased vascular permeability.,

Targeted studies have shown that the plasma from preeclamptic women is able to elicit specific responses in human ECs in vitro. ${ }^{4}$ Thus, incubation of ECs with preeclamptic plasma increases the expression and the production of ET-1, platelet-derived growth factor, vascular cell adhesion molecule 1 (VCAM-1), intercellular adhesion molecule 1 (ICAM1), cellular fibronectin, chemokines, cytokines, inducible nitric oxide (NO) synthase, NADPH oxidase 2 (NOX2), prostacyclines, NO, and reactive oxygen species (ROS)..$^{4-14}$ These studies support the idea that preeclamptic plasma contains factors able to trigger EC dysfunction.

In addition to these targeted studies, only one study, published in 2005, has investigated the effects of preeclamptic plasma on the global gene expression profiles of ECs. ${ }^{15}$ In this work, the authors used microarrays to analyze the in vitro gene expression profiles of human umbilical vein endothelial cells (HUVECs) and human glomerular microvascular endothelial cells after 24-hour exposition to preeclamptic or matched control plasma. However, they could not detect substantially altered gene expression by preeclamptic factors, except for a modest induction of IL-8 (approximately 1.5-fold). Therefore, they concluded that there are few endothelium-activating factors in the plasma of preeclamptic patients that can directly activate ECs. They hypothesized that the technical limitations of the 2005 microarrays were part of the reason why only mild modifications were detected, prompting us to perform a new study. Therefore, they performed a transcriptomic study on an immortalized HUVEC line exposed to plasma from normotensive or preeclamptic pregnancies. They found modifications of gene pathways, which could be involved in long-term endothelial dysfunction. Most interestingly, several genes in these pathways present a possible regulation through the Jun family of transcription factors [ie, an enrichment in activation protein-1 (AP-1) binding sites]. Because the AP-1 negative regulator, Jun dimerization protein 2 (JDP2), was among the most down-regulated genes by exposure to preeclamptic plasma, they analyzed its direct implication through siRNA knockdown experiments. Our results suggest that JDP2 is one of the factors responsible for endothelial transcriptional modifications in the preeclamptic patients.

\section{Materials and Methods}

\section{Sample Collection, Processing, and Validation}

Frozen plasma samples from women with normal or preeclamptic pregnancies were obtained from a previous epidemiological unpublished study. In all cases, informed consent was obtained. The local ethics committee of Federative Research Institute 48 (Marseilles, France) approved the use of the samples for the present project (agreement 08-012). Preeclampsia was defined using the criteria of gestational hypertension and proteinuria. Gestational hypertension was defined as new-onset systolic blood pressure $>140$ or diastolic pressure $>90 \mathrm{~mm} \mathrm{Hg}$ after 20 weeks' gestation. Proteinuria was defined as $>300 \mathrm{mg} / 24$-hour urine collection. Proteinuria was measured using dipstick test. All preeclamptic plasmas showed traces $>300 \mathrm{mg} / \mathrm{dL}$, corresponding to an approximate of 1 to $2 \mathrm{~g} / 24$ hours. Blood samples were collected in $10 \mathrm{~mL}$ EDTA-tripotassium Vacutainer tubes (Becton Dickinson, San Jose, CA). Within 1 hour, the tubes were centrifuged for 15 minutes at $700 \times g$ and $4{ }^{\circ} \mathrm{C}$ to remove blood cells. Plasma samples were divided into aliquots and stored at $-80^{\circ} \mathrm{C}$. Clinical characteristics of women who provided the blood used in the study are listed in Table 1. Plasma was obtained from two groups: a group of normotensive women with uncomplicated pregnancies and a group of preterm pregnant preeclamptic women. At the moment of blood collection, the control group $(n=10)$ had an average gestational age of 36 weeks (range, 28 to 40 weeks) and had no history of hypertension, diabetes, or infection. The preeclamptic group $(n=$ 10) was composed of women with preeclampsia with an average gestational age at the moment of blood sampling of 32 weeks (range, 27 to 36 weeks). On the basis of blood pressure and proteinuria values, most of the women of this group could be categorized as having severe preeclampsia. All of the procedures followed for the plasma and clinical data collection from the patients were in accordance with institutional guidelines. In addition to the clinical parameters, the plasma samples were further characterized by measuring the levels of tumor necrosis factor $\alpha$ (TNF- $\alpha)$ using Quantikine human TNF- $\alpha$ immunoassay (R\&D Systems, Minneapolis, MN) and soluble VCAM-1 using Quantikine human soluble VCAM-1 immunoassay (R\&D Systems). The levels of both TNF- $\alpha$ and soluble VCAM-1 were found significantly elevated in the 
Table 1 Clinical Data of the Preeclamptic and Matched Pregnant Control Women Included in the Study

\begin{tabular}{|c|c|c|c|}
\hline Data & Normal pregnancy $(n=10)$ & Preeclampsia $(n=10)$ & $P$ value \\
\hline Maternal age (years) & $31.5(29-34)$ & $31(29.5-35)$ & \\
\hline Gestational age (weeks) & $38(32-39)$ & $30(30-33.5)$ & 0.03 \\
\hline White & 5 & 6 & \\
\hline African & 4 & 3 & \\
\hline Others & 1 & 1 & \\
\hline Diastolic blood pressure $(\mathrm{mm} \mathrm{Hg})$ & $70(70-80)$ & $100(94-100)$ & $4.8 \times 10^{-5}$ \\
\hline Proteinuria $(\mathrm{mg} / \mathrm{dL}) *$ & 0 & $>300$ & \\
\hline
\end{tabular}

Differences between the preeclamptic and control group were analyzed using a Mann-Whitney nonparametric test. Data are given as medians (75\% CIs), based on the interquartile range.

*Proteinuria was measured with a dipstick test, and levels were $>300 \mathrm{mg} / \mathrm{dL}$ (approximately 1 to $2 \mathrm{~g} / 24$ hours).

plasma samples of preeclamptic women when compared with matched controls (Supplemental Figure S1). These analyses corroborate previous studies and indicate increased EC activation and inflammatory status in the preeclamptic women included in this study.

\section{Endothelial Cell Cultures}

An HUVEC line immortalized with the large T-antigen of SV40 and ectopic expression of the human telomerase reverse transcriptase was used in this study. ${ }^{16}$ Since the establishment of this cell line, its phenotype has been maintained over passages. Cells were routinely cultured in uncoated $75-\mathrm{cm}^{2}$ tissue culture flasks at $37^{\circ} \mathrm{C}$ and $5 \% \mathrm{CO}_{2}$. Culture medium consisted of Dulbecco's modified Eagle's medium supplemented with $10 \%$ (v/v) heat-inactivated fetal calf serum (FCS), $2 \mathrm{mmol} / \mathrm{L}$ GlutaMAX (L-alanyl-L-glutamine; Invitrogen, Life Technologies, Carlsbad, CA), $5 \mathrm{IU} / \mathrm{mL}$ heparin, $100 \mathrm{IE} / \mathrm{mL}$ penicillin, and $100 \mathrm{mg} / \mathrm{mL}$ streptomycin. In addition, we used an immortalized human microvascular cell line, the human dermal microvascular endothelial cell (HMEC)-1, to confirm our results on most modified genes. The culture medium for the HMEC-1 consisted of MCDB-131 supplemented with $10 \%$ (v/v) heat-inactivated FCS, $0.2 \mu \mathrm{g} / \mathrm{mL}$ hydrocortisone, $10 \mathrm{ng} / \mathrm{mL}$ epidermal growth factor, $2 \mathrm{mmol} / \mathrm{L}$ GlutaMAX, $5 \mathrm{IU} / \mathrm{mL}$ heparin, $100 \mathrm{IE} / \mathrm{mL}$ penicillin, and $100 \mathrm{mg} / \mathrm{mL}$ streptomycin.

\section{Endothelial Monolayer Permeability}

Endothelial monolayer permeability was assessed by the passage of fluorescein isothiocyanate-conjugated dextran $(0.1 \mathrm{mg} / \mathrm{mL}, 40 \mathrm{kDa}$; Invitrogen $)$, as previously described. ${ }^{17}$ Briefly, 100,000 HUVECs were plated onto 6.5-mm Transwell collagen-coated $3-\mu \mathrm{m}$ pore polytetrafluoroethylene membrane inserts (Costar, Corning Incorporated, New York, $\mathrm{NY}$ ), left for 3 days to form mature monolayers, and further starved for 16 hours. After 1 hour of stimulation with $10 \%$ preeclamptic or normal plasma, each sample from the bottom chamber was read on a fluorescent plate reader (FUSION; Packard BioScience Company, Meriden, CT).

\section{Experimental Design}

In all experiments, HUVECs were grown until forming $90 \%$ confluent monolayers. Then, cells were washed twice in PBS and serum starved for 12 hours. To study the effects of preeclamptic plasma factors on endothelial gene expression, serum-starved HUVECs were grown for 24 hours in culture medium devoid of FCS but supplemented with $10 \%(\mathrm{v} / \mathrm{v})$ plasma from preeclamptic patients or matched controls. To determine the responsiveness of HUVECs to proinflammatory stimulus, cells were incubated for 5 hours in complete culture medium with TNF- $\alpha$. The concentrations of TNF- $\alpha$ were $0.1,0.5,1$, and $5 \mathrm{ng} / \mathrm{mL}$.

\section{RNA Isolation}

Total RNA was isolated from HUVECs with TRIzol (Invitrogen Life Technology), according to the manufacturer's instructions, and treated with DNase I to eliminate genomic DNA contamination. The quality of the RNA was analyzed using the Bioanalyzer 2100 and the RNA 6000 nano LabChip kit (Agilent Technologies, Santa Clara, CA). Only total RNA samples with an RNA Integrity Number (RIN) $\geq 0.8$ were used.

\section{Agilent Oligonucleotide Microarrays}

For gene expression measurement, we used the Agilent whole genome microarray kit, Agilent human $8 \times 60 \mathrm{~K}$ (reference G4851A), interrogating a total of 27,958 Entrez gene RNAs and 7419 lincRNAs. The hybridizations were performed at the genomic and transcriptomic platform of the Cochin Institute (Paris, France), according to standardized procedures. Normalization and statistics were performed using Partek Genomic Suite (Saint Louis, MO). Raw data were preprocessed using quantile normalization, and log transformed. Unsupervised analysis on data allowed us to check nondesired experimental factors and biological outliers using hierarchical clustering (Pearson's dissimilarity and average linkage) and principal component analysis, including all samples. To avoid 
false-positive signals, we excluded the genes with an average expression level $<100$ from the analyses. In our experience, expression values from probes giving low absolute intensity signals are not reliable. To find differentially expressed genes, we applied a classic unpaired Student's $t$-test between compared groups and computed the fold-change for each gene. Then, we used these two statistics to filter and select differentially expressed genes. We selected genes with $P<0.05$ and fold-changes $<1.25$. The data sets were prepared according to the guidelines of minimum information for a microarray experiment and were deposited in the Gene Expression Omnibus (http://www.ncbi.nlm.nih.gov/geo; accession number GSE41681).

\section{Quantitative RT-PCR}

Quantitative RT-PCR was used to validate a subset of genes that showed differential expression in the HUVECs treated with preeclamptic plasma. Twelve genes were selected based on their fold differences and biological relevance. The RNA samples were reverse transcribed according to a standardized protocol. Briefly, $2 \mu \mathrm{g}$ of total DNase-treated RNA was reverse transcribed in a volume of $25 \mu \mathrm{L}$ at $39^{\circ} \mathrm{C}$ using the Superscript Reverse Transcriptase (Invitrogen) during 1 hour. Quantitative RT-PCR was performed in duplicate on eight control and nine preeclamptic samples. The amplification kit, LC480 SYBR Green Master Kit (Invitrogen), was used with $1 \mu \mathrm{M}$ specific primers to a final volume of $10 \mu \mathrm{L}$. The reaction was performed in a Light Cycler Thermocycler (Roche Applied Science, Mannheim, Germany). The primers (Table 2) were designed for the coding sequences (GENBANK) of the different genes to be analyzed using the
PRIMER3 software (http://simgene.com/Primer3). Different couples were chosen to cover all of the previously described isoforms and aligned with basic local alignment search tool software (http://blast.ncbi.nlm.nih.gov/Blast.cgi) to avoid non-specific annealing. We used the following PCR program: $95^{\circ} \mathrm{C}$ for 5 minutes, followed by 35 cycles of three temperature steps $\left(95^{\circ} \mathrm{C}\right.$ for 10 seconds, $55^{\circ} \mathrm{C}$ for 15 seconds, and $72^{\circ} \mathrm{C}$ for 15 seconds). Finally, samples were submitted to a progressive temperature elevation (from $65^{\circ} \mathrm{C}$ to $99^{\circ} \mathrm{C}$ at $0.1^{\circ} \mathrm{C} /$ second), resulting in a fusion curve, enabling us to check the homogeneity of the PCR products. In addition, amplification products were systematically controlled by agarose gel electrophoresis. The threshold cycle number $\left(\mathrm{C}_{\mathrm{T}}\right)$ values were collected with the LightCycler 480 software version 1.5 (Roche) using an automated second derivative method, in the exponential phase of the PCR. These $\mathrm{C}_{\mathrm{T}}$ values were normalized by the $\mathrm{C}_{\mathrm{T}}$ values obtained for the reporter genes, succinate dehydrogenase subunit A (SDHA) and glyceraldehyde-3-phosphate dehydrogenase (GAPDH).

\section{Functional Clustering by DAVID}

Two lists of genes induced or repressed in the HUVECs cultured with preeclamptic plasma were submitted to the DAVID database. ${ }^{18,19}$ Briefly, DAVID clusters genes from a list according to a series of keywords common to several genes from the list. The proportion of each keyword from the gene list submitted is compared with the proportion in the whole genome, making it possible to compute a $P$ value. Enrichment values are then calculated as the geometric mean of the inverse $\log$ of each $P$ value.

Table 2 Primers Used in the Quantitative RT-PCR Analysis

\begin{tabular}{|c|c|c|c|}
\hline Gene & Forward primer & Reverse primer & Amplicon size (bp) \\
\hline NOX4 & $5^{\prime}-$ TGCCATGAAGCAGGACTCTA-3' & $5^{\prime}$-GCCACATTCTCACATTTCCA-3' & 144 \\
\hline BIRC5 & $5^{\prime}$-CATAGAGCTGCAGGGTGGAT-3' & $5^{\prime}-\mathrm{AAAACCCAGTAGGGTCCACA-3^{ \prime }}$ & 120 \\
\hline CEBPB & $5^{\prime}-$ CGTGTGTACACGGGACTGAC-3' & 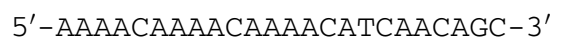 & 110 \\
\hline ATF4 & 5'-CCTGAAAGATTTGATAGAAGAGGTC-3' & $5^{\prime}-\mathrm{TGGAACACACAGCTACAGCA-3^{ \prime }}$ & 118 \\
\hline VEGFA & $5^{\prime}$-GGATCAAACCTCACCAAGG-3' & 5'-CСTTTCCTCGAACTGATTTTT-3' & 120 \\
\hline$B C L 2 A 1$ & $5^{\prime}$-GGCATCATTAACTGGGGAAG-3' & 5'-TGAAATCTCCTTATAGGTATCCACA-3' & 114 \\
\hline CCNA2 & $5^{\prime}$-CGCTGGCGGTACTGAAGTC-3' & 5'-GAGGAACGGTGACATGCTCAT-3' & 120 \\
\hline $\operatorname{CDC20}$ & $5^{\prime}$-GCACAGTTCGCGTTCGAGA-3' & $5^{\prime}$-CTGGATTTGCCAGGAGTTCGG-3' & 188 \\
\hline ADAMTSL1 & 5'-GGGGCCTCCTAСТСTCTGAG-3' & 5'-AGTCCACATTACTGCATGTTCTG-3' & 88 \\
\hline ID3 & 5'-CATCGACTACATTCTCGACCTG-3' & 5'-TCCTTTTGTCGTTGGAGATGAC-3' & 128 \\
\hline$A P L N$ & 5'-GTCTCCTCCATAGATTGGTCTGC-3' & $5^{\prime}$-GGAATCATCCAAACTACAGCCAG-3' & 149 \\
\hline TGM2 & 5'-GAGGAGCTGGTCTTAGAGAGG-3' & $5^{\prime}-$ CGGTCACGACACTGAAGGTG-3' & 184 \\
\hline GAPDH & $5^{\prime}-\mathrm{AACAGCGACACCCATCCTC-3^{ \prime }}$ & $5^{\prime}$-CATACCAGGAAATGAGCTTGACAA-3' & 81 \\
\hline IGFBP3 & $5^{\prime}$-CTGTGGCCATGACTGAGGAAAG-3' & $5^{\prime}-$ TCCCTGAGCCTGACTTTGCC-3' & 97 \\
\hline$J D P 2$ & $5^{\prime}$-GATGCCGGAACAAGAAGAAG-3' & 5'-GCTTCAGCTCCTCAATCTGG-3' & 105 \\
\hline SDHA & 5'-TACAAGGTGCGGATTGATGA-3' & $5^{\prime}$-CAAAGGGCTTCTTCTGTTGC-3' & 66 \\
\hline
\end{tabular}


Functional Clustering and Biological Pathway Analysis with GENOMATIX

A list of statistically significant differentially expressed genes between HUVECs treated with normal or preeclamptic plasma was generated. This list was analyzed with several GENOMATIX tools, including GeneRanker and the Pathway analysis tool GePS (http://www.genomatix.delen/ index.html). The genes modified $>1.25$-fold were submitted as text files with the level of induction/repression. This allowed us to generate pathways with a threshold for significance in the gene clustering established at $P<0.05$.

\section{Pathological Association Testing}

To assess the potential role of the differentially expressed genes in pathology, we used the GENOMATIX diseases Medical Subject Headings (MeSH) tool. This analysis allowed testing for an eventual association between the list of modified genes and specific keywords associated with preeclampsia, including preeclampsia, hypertension, inflammation, cardiovascular disease, and inflammation.

\section{Promoter Analysis}

The set of modified genes identified by microarray analysis was submitted to promoter analysis to identify regulatory mechanisms. The GENOMATIX Gene to Promoter tool was used to analyze the promoter regions of these genes, searching for mammalian transcription factor binding sites. A background set of promoter sequences was extracted in a similar manner using a set of unmodified genes from our microarray study. A sequence-specific overrepresentation was calculated using a $t$-test for comparing the content of a given promoter in a given putative transcription factor binding site. The statistical values were corrected by strict Bonferroni corrections, requesting a $P$ value of $2 \times 10^{-4}$, given the independent test of 180 putative binding sites $(0.05 / 180)$.

\section{JDP2 Gene Silencing}

HUVECs were plated in Dulbecco's modified Eagle's medium/GlutaMAX and $10 \%$ fetal bovine serum on day 0 , and were transfected with 10 pmol of siRNA oligonucleotides targeting human JDP2 (Qiagen, Hilden, Germany) or nontargeting controls using Lipofectamine RNAiMAX (Qiagen) on day 1 , in serum-free medium. The control siRNA sequence of the sense strand was 5'-UAGCAAUGACGAAUGCGUAdTdT- $3^{\prime}$. The sense and antisense sequences of the duplex specific for human JDP2 were 5'-GCCAUGAGUUGCAACCAAATT-3' and 5'-UUUGGUUGCAACUCAUGGCTT- $3^{\prime}$, respectively. After 6 hours, the medium was changed to complete medium. Total RNA was extracted after 48 hours and processed for quantitative RT-PCR. JDP2 siRNA silencing was performed in association with human plasma treatment. In this case, after 6 hours of transfection, the medium was changed to complete medium; and after 24 hours, cells were incubated with $10 \%(\mathrm{v} / \mathrm{v})$ plasma from normal pregnancies for 24 hours and total RNA was extracted.

\section{Statistics}

Microarray analysis was analyzed using DAVID and GENOMATIX, for gene clustering. ${ }^{18}$ GENOMATIX was also used for promoter analysis. Clinical parameters of the patients were analyzed using the Mann-Whitney test. Validation performed by quantitative RT-PCR was analyzed by Student's $t$-test. $P<0.05$ was considered significant.

\section{Results}

\section{Validation of the Endothelial Cell Line Used in the Study}

An immortalized HUVEC line was used to ensure the reproducibility of the results. In PE, expression of markers of proinflammatory endothelial activation and increased vascular permeability have been consistently reported. Therefore, to verify that the chosen HUVEC line was appropriate for our study, we determined its response to proinflammatory stimuli and evaluated its response to preeclamptic plasma in terms of permeability. We verified that the HUVEC line was responsive to proinflammatory stimuli by treating it with TNF- $\alpha(0.1,0.5$, 1 , or $5 \mathrm{ng} / \mathrm{mL}$ ) and measured the expression of several endothelial markers after a 5-hour exposition. This resulted in a dose-response up-regulation of several endothelial activation markers, including IL-1, IL-8, VCAM-I, ICAM-I, and Eselectin (Supplemental Figure S2). Also, we conducted an assay to compare the permeability of the HUVECs exposed to preeclamptic or normal pregnant plasma. This analysis showed that the preeclamptic plasma samples significantly increased the permeability of the HUVEC line, confirming that these cells display another of the characteristic response of ECs to PE (Supplemental Figure S3). Therefore, the selected HUVEC line meets basic criteria necessary to analyze the transcriptional effects of preeclamptic plasma factors on the ECs.

\section{Microarray Analysis of the HUVECs Treated with Preeclamptic Plasma}

The HUVECs were incubated for 24 hours with plasma from either preeclamptic or matched normal pregnant female plasma, and gene-expression profiles were analyzed with DNA microarrays interrogating 27,958 genes. In the preeclamptic plasmatreated HUVECs, 71 genes were significantly up-regulated and 45 were down-regulated compared with HUVECs incubated with normal pregnant plasma. Table 3 lists a selection of the differentially expressed genes with $P<0.05$ (a full list of modified genes is given in Supplemental Table S1). We then used the DAVID version 6.7 and GENOMATIX software programs to perform functional and network analyses. This allowed us to identify gene classifiers and pathways that are 
Table 3 Differentially Expressed Genes in the HUVECs Treated with Preeclamptic Plasma

\begin{tabular}{|c|c|c|}
\hline Gene symbol & Gene name & Fold change \\
\hline \multicolumn{3}{|c|}{ Up-regulated genes } \\
\hline EDN1 & Endothelin-1 & 1.88 \\
\hline ADAMTSL1 & ADAMTS-like 1 & 1.79 \\
\hline ID3 & Inhibitor of DNA binding 3 & 1.74 \\
\hline NOX4 & NADPH oxidase 4 & 1.69 \\
\hline INSIG1 & Insulin-induced gene 1 & 1.59 \\
\hline$B C L 2 A 1$ & $\mathrm{BCL} 2$-related protein $\mathrm{A} 1$ & 1.53 \\
\hline HIST1H1D & Histone cluster $1, \mathrm{H} 1$ days & 1.44 \\
\hline$C D C 20$ & Cell division cycle 20 homolog & 1.43 \\
\hline$A P L N$ & Apelin & 1.43 \\
\hline FASN & Fatty acid synthase & 1.38 \\
\hline SPARC & Secreted protein, acidic, cysteine rich & 1.37 \\
\hline CCNB1 & Cyclin B1 & 1.37 \\
\hline PSRC1 & Proline/serine-rich coiled-coil 1 & 1.36 \\
\hline CBR3 & Carbonyl reductase 3 & 1.34 \\
\hline KIF20A & Kinesin family member $20 \mathrm{~A}$ & 1.34 \\
\hline$H M M R$ & Hyaluronan-mediated motility receptor & 1.33 \\
\hline ICAM2 & Intercellular adhesion molecule 2 & 1.32 \\
\hline NEK2 & NIMA (never in mitosis gene a)-related kinase 2 & 1.32 \\
\hline HSPA5 & Heat shock $70-k D a$ protein 5 & 1.28 \\
\hline BIRC5 & Baculoviral IAP repeat-containing 5 & 1.28 \\
\hline CDCA8 & Cell division cycle-associated 8 & 1.27 \\
\hline CCNA2 & Cyclin A2 & 1.27 \\
\hline LOXL2 & Lysyl oxidase-like 2 & 1.27 \\
\hline KPNA2 & Karyopherin $\alpha 2$ & 1.26 \\
\hline PTTG1 & Pituitary tumor-transforming 1 & 1.25 \\
\hline TGFBI & Transforming growth factor, $\beta$ induced & 1.25 \\
\hline \multicolumn{3}{|c|}{ Down-regulated genes } \\
\hline NFIL3 & Nuclear factor, IL-3, regulated & -1.34 \\
\hline CITED2 & $\mathrm{Cbp} / \mathrm{p} 300$-interacting transactivator & -1.35 \\
\hline STC2 & Stanniocalcin 2 & -1.44 \\
\hline CAMK2N1 & Calcium/calmodulin-dependent protein kinase II inhibitor & -1.47 \\
\hline ATF4 & Activating transcription factor 4 & -1.50 \\
\hline VEGFA & Vascular endothelial growth factor A & -1.50 \\
\hline TXNIP & Thioredoxin-interacting protein & -1.53 \\
\hline KLF9 & Kruppel-like factor 9 & -1.68 \\
\hline$C B S$ & Cystathionine- $\beta$-synthase & -1.69 \\
\hline TSC22D3 & TSC22 domain family, member 3 & -1.86 \\
\hline IGFBP3 & Insulin-like growth factor binding protein 3 & -1.93 \\
\hline TRIB3 & Tribbles homolog 3 & -1.96 \\
\hline CEBPB & CCAAT/enhancer binding protein, $\beta$ & -2.02 \\
\hline DDIT4 & DNA damage-inducible transcript 4 & -2.15 \\
\hline JDP2 & Jun dimerization protein 2 & -2.67 \\
\hline CHAC1 & Cation transport regulator homolog 1 & -2.88 \\
\hline
\end{tabular}

Partial list of genes displaying significantly modified expression $(P<0.05)$ between the HUVECs exposed to preeclamptic plasma and those exposed to plasma from normal pregnant women.

significantly enriched in HUVECs treated with preeclamptic plasma (Table 4). Expression levels of genes involved in cell cycle control and progression were increased in HUVECs treated with preeclamptic plasma, such as PTTG1, CCNB1, CCNA2, TXNIP, PLK1, PSRC1, CDC20, KPNA2, CKAP2, $C D C A 8, S P H K 1$, and ID3. Interestingly, we found that $J D P 2$, a member of the AP-1 family known to suppress cell cycle progression, was down-regulated. ${ }^{20}$ Another category of upregulated genes was composed of inhibitors of the apoptotic process (BCL2A1, BIRC5, SPHK1, HSPA5, and RTEL1), whereas the pro-apoptotic genes PMAIP1, PHLPP1, DDIT4, $I G F B P 3$, and $C H A C 1$ were found to be down-regulated. $C H A C 1$ and five other down-regulated genes (ATF4, CEBPB, TRIB3, XBP-1, and DDIT4) are components of the unfolded protein response (UPR) pathway. This pathway constitutes a response to endoplasmic reticulum (ER) stress, and its activation is a feature of many chronic inflammatory and autoimmune diseases. ${ }^{21}$ HSPA5 (alias BiP), which is up-regulated in our study, has been described as a master regulator of the antiapoptotic UPR signaling network. ${ }^{22}$ Several modified genes 
Table 4 Most Representative Overrepresented Biological Functions Identified by the DAVID and GENOMATIX Software in HUVECs Treated with Preeclamptic Plasma vs Normal Pregnancy Plasma

\begin{tabular}{|c|c|c|c|}
\hline Functional category & $\begin{array}{l}\text { No. of } \\
\text { genes }\end{array}$ & Gene symbol & $P$ value \\
\hline \multicolumn{4}{|l|}{ DAVID Functional Annotation Chart } \\
\hline Cell cycle & 13 & $\begin{array}{l}\text { CKAP2, TXNIP, TRNP1, CASC5, CDC20, BIRC5, PTTG1, SMC4, CCNB1, } \\
\text { CDCA8, SPAG5, PLK1, CCNA2 }\end{array}$ & $1.30 \times 10^{-5}$ \\
\hline Apoptosis & 11 & $\begin{array}{l}\text { PHLPP1, CKAP2, TSC22D3, CHAC1, BCL2A1, TRIB3, BIRC5, PMAIP1, } \\
\quad \text { RTEL1, PHLDA1, DDIT4 }\end{array}$ & $6.67 \times 10^{-5}$ \\
\hline Negative regulation of apoptosis & 9 & CEBPB, VEGFA, SPHK1, BCL2A1, RAG1, BIRC5, HSPA5, RTEL1, CITED2 & $2.61 \times 10^{-3}$ \\
\hline \multicolumn{4}{|l|}{ GENOMATIX Gene Ranker Analyzer } \\
\hline M phase of the mitotic cell cycle & 15 & CDCA8, SPAG5, SMC4, KIF20A, EDN1, INSR, BIRC5, CASC5, CCNB2 & $8.45 \times 10^{-9}$ \\
\hline Cell cycle & 23 & $\begin{array}{l}\text { PTTG1, CCNB1, CCNA2, TXNIP, PLK1, PSRC1, CDC20, KPNA2, CKAP2, } \\
\text { CDCA8, SPHK1, SPAG5, GAS2L3, CITED2, SMC4, TRNP1, KIF2OA, } \\
\text { EDN1,ID3, INSR, BIRC5, CASC5, CCNB2 }\end{array}$ & $2.99 \times 10^{-6}$ \\
\hline Response to hypoxia & 6 & CCNB1, VEGFA, DDIT4, STC2, CITED2, EDN1 & $6.50 \times 10^{-4}$ \\
\hline Positive regulation of locomotion & 6 & ITGB3, SLIT2, VEGFA, SPHK1, EDN1, INSR & $6.50 \times 10^{-4}$ \\
\hline Cardiovascular system development & 11 & $\begin{array}{l}\text { ADAMTS1, CCNB1, ITGB3, SLIT2, VEGFA, SPHK1, CITED2, ERRFI1, } \\
\text { EDN1, ID3, INSR }\end{array}$ & $8.98 \times 10^{-4}$ \\
\hline Anti-apoptosis & 6 & HSPA5, SPHK1, CITED2, CEBPB, BCL2A1, BIRC5 & $6.41 \times 10^{-3}$ \\
\hline Cellular response to stress & 14 & $\begin{array}{l}\text { PTTG1, CCNB1, CCNA2, ZSWIM7, PMAIP1, PLK1, ATF4, HSPA5, VEGFA, } \\
\text { INSIG1, CBS, STC2, RTEL1, EDN1 }\end{array}$ & $2.00 \times 10^{-3}$ \\
\hline
\end{tabular}

Up-regulated genes in HUVECs treated with preeclamptic plasma are boldfaced, and down-regulated genes are not.

are involved in fatty acid biosynthesis, including INSIGI, $F A S N$, and $A G M O$, which are all targets of sterol regulatory element binding protein (SREBP). Moreover, genes involved in cardiovascular development (ADAMTS1, CCNB1, ITGB3, SLIT2, VEGFA, SPHK1, CITED2, ERF11, EDN1, ID3, and $I N S R$ ) and endothelial vasoregulation (EDN1, APLN, CBS, and NOX4) were identified.

\section{Pathological Association Testing}

To further pursue the in silico analysis, the lists of upregulated and down-regulated genes were submitted to the GENOMATIX Gene Ranker tool and the resulting Diseases (MeSH) table screened for terms related to preeclampsia (Table 5). This allowed the association of modified genes and disease-associated keywords. The test indicated that several $\mathrm{MeSH}$ annotations were significantly overrepresented in our list of modified genes, including pregnancy complications, cardiovascular diseases, vascular diseases, hypertension, pregnancy-induced inflammation, and preeclampsia.

Validation of Differential Gene Expression by Quantitative Real-Time RT-PCR

Microarray data were validated by quantitative real-time RT-PCR using specific primers for a selected subset of genes found differentially expressed (Figure 1, A and B). The genes were selected according to their fold change and/ or their putative functional relevance. Thus, EDN1 and $J D P 2$ are two of the most modified genes in our study, with fold changes of 1.88 and -2.67 , respectively. Other selected genes are representative of the biological functions that appear overrepresented when performing functional analysis, using the DAVID version 6.7 or GENOMATIX (Munich, Germany) software (CDC20 is involved in the cell cycle, and BCL2AI, ID3, and IGFBP3 are involved in apoptosis regulation). This analysis was conducted on HUVECs incubated for 24 hours with plasma samples of 10 preeclamptic women and compared with the results obtained with 10 plasma samples from normal pregnant women. This way, we validated the modified expression of $E D N 1, A P L N$, NOX4, TGM2, CDC20, BCL2A1, BIRC5, ID3, INSIG1, $J D P 2, I G F B P 3$, and VEGFA. In addition, we tested the gene modifications in two groups of patients (severe cases: $n=5$; average time for plasma collection, 32 weeks; and mild cases: $n=7$; average time for plasma collection, 36 weeks). We did not find significant differences in gene expression alterations between the groups, except for $E D N 1$, which was increased 1.8-fold in mild PE and 2.7-fold in severe PE $(P=0.002)$, suggesting that, except for this factor, the modifications observed are general for preeclampsia (Supplemental Figure S4). 
Table 5 GENOMATIX Disease MeSH Terms Associated with the List of Modified Genes in HUVECs Exposed to Preeclamptic Plasma

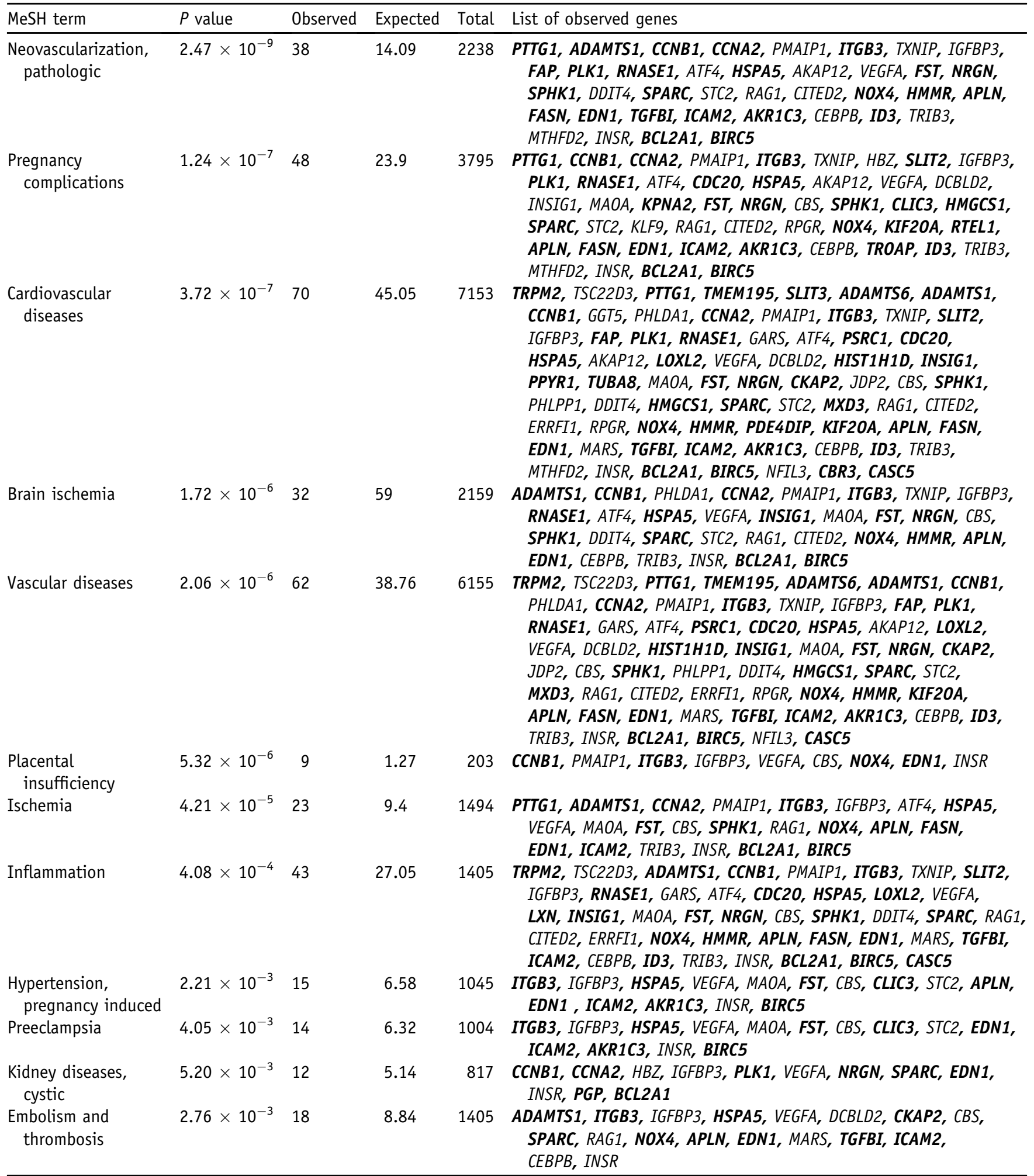

Up-regulated genes in HUVECs treated with preeclamptic plasma are boldfaced, and down-regulated genes are not.

Promoter Analysis

To identify master genes of the preeclamptic plasma-induced transcriptomic modifications, we proceeded to an analysis of the predicted binding sites for transcription factors present in the promoters of the differentially expressed genes. The occurrence of binding sites for transcription factors was obtained from the MatInspector Genomatix software for the 

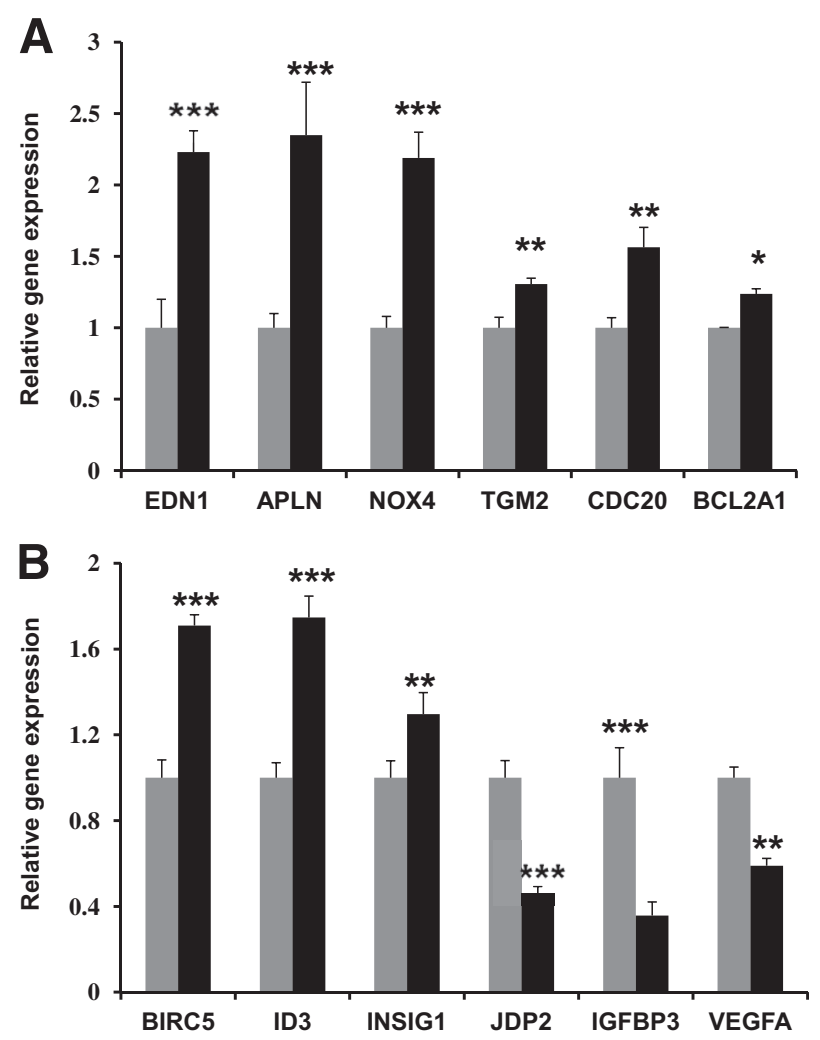

Figure 1 Validation of differentially expressed genes in HUVECS exposed to preeclamptic plasma. Selected differentially expressed genes in HUVECs exposed to preeclamptic plasma were analyzed by quantitative realtime RT-PCR to validate the results obtained with the DNA-microarray experiment (A and B). Relative gene expression values were adjusted to the mean value of the control group ( $\mathrm{Co}$; untreated cells) set at 1 for each gene. Gray bars, control group; black bars, preeclampsia. ${ }^{*} P<0.05,{ }^{*} P<$ 0.01 , and ${ }^{* *} P<0.0001$ using the Student's $t$-test.

promoters of 44 most up-regulated, 9 most down-regulated, and a sample of 57 nonmodified genes. This allowed the identification of overrepresentation in the modified gene set of putative transcription factor binding sites for AP-1 $(P<$ 0.0024; $P<0.0005$ when only the induced genes were compared with the unmodified set). Interestingly, JDP2, one of the most down-regulated $(-2.67)$ genes in the HUVECs exposed to preeclamptic plasma, encodes the Jun dimerization protein 2 , a member of the AP-1 family that functions as a repressor of the AP-1-dependent transcription.

\section{Role of JDP2 in the Transcriptomic Response of HUVECs to Preeclamptic Plasma}

To focus on the role of JDP2 in the transcriptomic activation of AP-1-regulated genes induced by the preeclamptic plasma, HUVECs were treated with an siRNA targeting JDP2 (siJDP2). The cells were transfected with either the siJDP2 or a control (scrambled) siRNA and cultured for 24 hours in a medium supplemented with $10 \%$ normal plasma from pregnant women. Subsequently, quantitative RT-PCR was used to analyze the expression of 18 genes, containing $(n=8)$ or lacking $(n=10)$ AP-1 regulatory sites in their proximal promoters. As shown in Figure 2, siJDP2 reduced the levels of JDP2 mRNA in the HUVECs by $75 \%$. JDP2 knockdown resulted in significantly increased expression levels of three genes (CAMK2N1, BCL2Al, and CEBPB). Of these genes, only two (BCL2Al and $C E B P B)$ are known to contain AP-1 regulatory sites in their promoter. The siRNA JDP2 silencing resulted in significant down-regulation of 11 genes, 6 of them containing AP-1 sites (EDN1, TGM2, $C D C 20, I D 3, E 2 F 1$, and $C C N A 2)$. Finally, the siRNA JDP2 had no effect on the expression of nine genes. Of these genes, three contained AP-1 sites in their promoters (NOX4, INSIGI, and ATF4). The same experiment was repeated using another endothelial cell line, the HMEC-1, to determine whether the effects of JDP2 down-regulation were restricted to the HUVEC line. This analysis showed that, in general, the genes modified by JDP2 siRNA in the HUVECS are overall modified with a similar expression profile in HMEC-1, albeit with a decreased intensity, some of them being unmodified, such as EDN1 (Supplemental Figure S5).

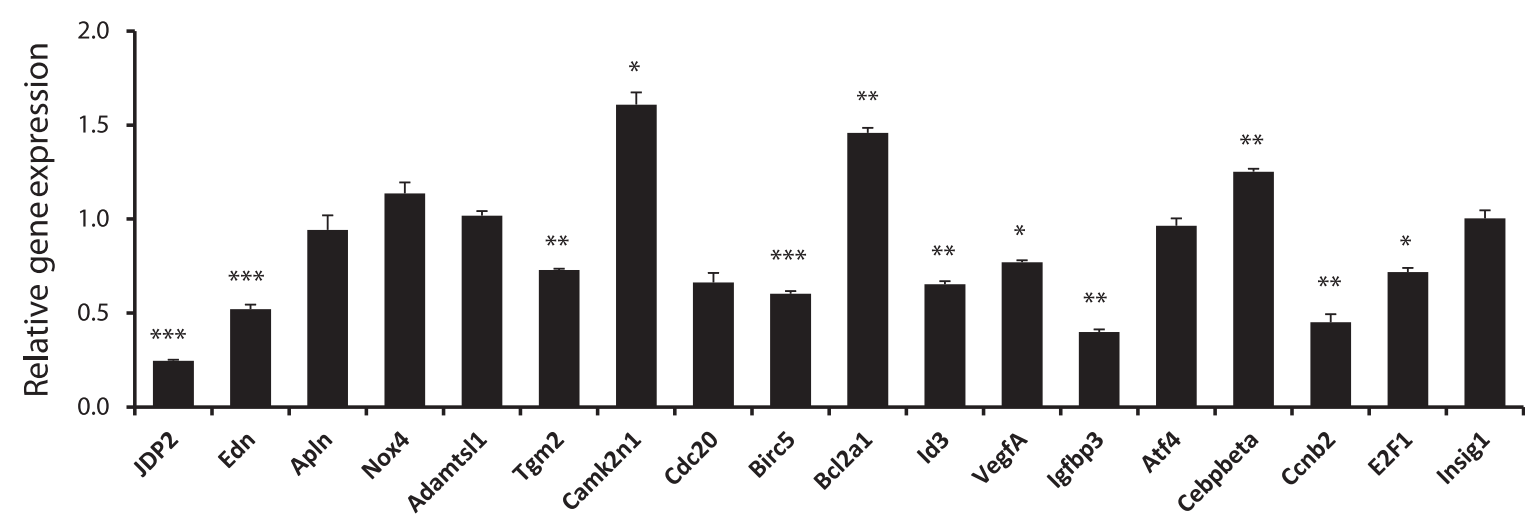

Figure 2 Effect of JDP2 knockdown on the expression of preeclamptic plasma deregulated genes. To inhibit JDP2 expression, HUVECs were transfected with 30 pmol of siRNA specific for JDP2 (siJDP2). The same amount of nonspecific double-stranded RNA was used as a negative control (siCO). Two days after the transfection, the cells were harvested and total RNA was subjected to quantitative RT-PCR using primers specific for JDP2 and for several genes found to be modified by the preeclamptic plasma. Levels of expression were normalized to that of GAPDH and SDHA. Data are shown as relative gene expression values adjusted to the mean value of the control group (siC0), which was set at 1 for each gene. Error bars represent the SD. ${ }^{*} P<0.05, * * P<0.01,{ }^{* *} P<0.0001$ using the student's $t$-test. 


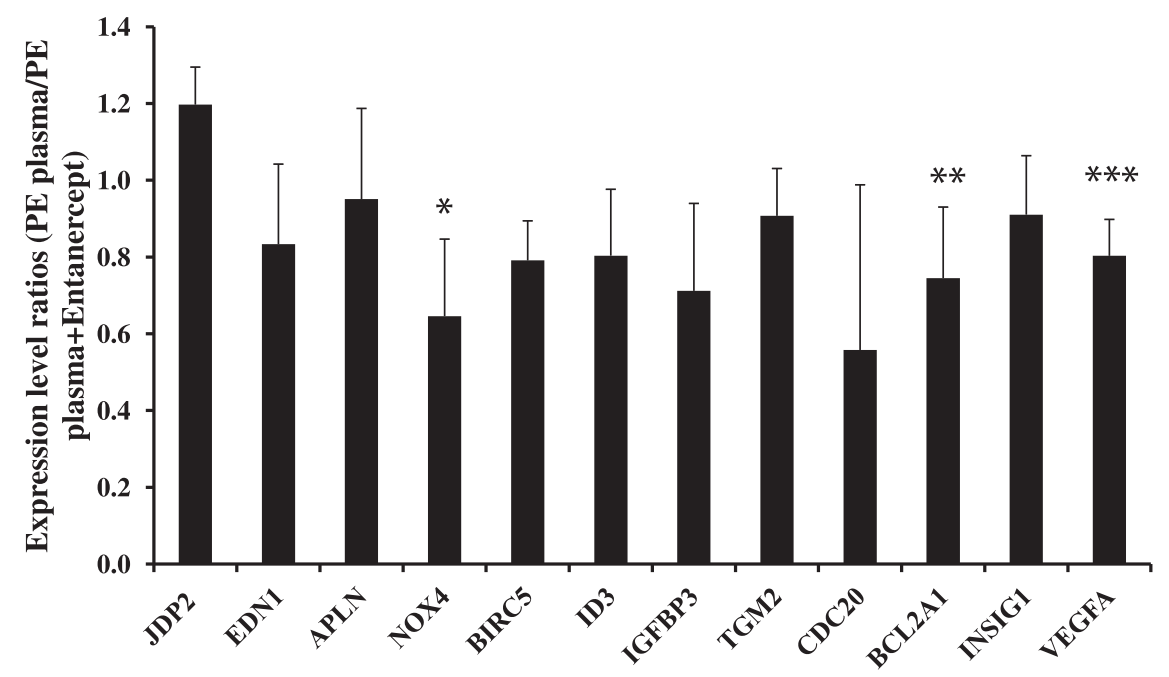

Figure 3 Effects of TNF- $\alpha$ inhibition on the expression of a selection of genes modified by preeclampic plasma. HUVECs were cultured for 24 hours in quadruplicate, in the presence of preeclamptic plasma with or without $10 \mu \mathrm{g} / \mathrm{mL}$ of the TNF- $\alpha$ inhibitor, etanercept. Subsequently, the expression of several genes found to be modified by the preeclamptic plasma in the previous experiments was analyzed using quantitative RT-PCR. Expression ratios, with or without etanercept, are shown for the 12 genes analyzed (a ratio of 1 meaning no effect of TNF- $\alpha$ inhibition). Inhibition of TNF- $\alpha$ signaling had a significant effect only on NOX4 expression. ${ }^{*} P=0.02$. A trend was, however, observed for BCL2A1 ( $\left.{ }^{* *} P=0.07\right)$ and VEGFA $\left({ }^{* *} P=0.08\right)$. Error bars represent the SDs.
TNF- $\alpha$ Mediates Some Effects of Preeclamptic Plasma on Endothelial Cells but Does Not Regulate JDP2 Expression

TNF- $\alpha$ is known to induce proinflammatory activation in ECs, and increased circulating levels have been reported in preeclampsia. Indeed, the measurements of cytokine levels in the plasma samples of the women used in our study indicates that the TNF- $\alpha$ levels are significantly higher in the plasma samples from preeclamptic women $(1.5 \mathrm{pg} / \mathrm{mL})$ than in the controls $(0.5 \mathrm{pg} / \mathrm{mL})$ (Supplemental Figure S1). Thus, we investigated whether some of the gene expression modifications induced by the preeclamptic plasma were caused by the increased levels of TNF- $\alpha$, and if they were related to $J D P 2$ down-regulation. To this end, HUVECs were treated for 24 hours with preeclamptic plasma in the presence or absence of etanercept (an inhibitor of TNF- $\alpha$ ). Subsequently, the expression of some genes (JDP2, EDN1, APLN, NOX4, BIRC5, ID3, IGFBP3, TGM2, BCL2A1, INSIG1, and $V E G F A$ ), which were found significantly modified in the microarray analysis, were analyzed by quantitative PCR. We found that TNF- $\alpha$ inhibition did not block the downregulation of JDP2 induced by the preeclamptic plasma, suggesting that this effect is mediated by other factors. Among the 12 genes tested, we observed that etanercept was able to bring the expression levels of one of them, NOX4 (not modulated by JDP2), back to the level of expression in HUVECs treated with control plasma; it was induced more than twofold by preeclamptic plasma alone (Figure 3), suggesting that NOX4 regulation passes through TNF- $\alpha$ activation in a $J D P 2$-independent pathway. Reciprocally, it suggests that increased TNF- $\alpha$ levels account only for a subset of genes modified in preeclamptic plasma-treated ECs.

\section{Discussion}

In this study, we have analyzed the effects of plasma from women with either preeclamptic or normal pregnancies on the global gene expression profile of immortalized HUVECs that were exposed for 24 hours to preeclamptic or normal pregnancy plasma. We detected 116 genes with significantly modified expression in cells exposed to plasma from preeclamptic versus normal pregnancies. Some of these genes are most relevant to EC pathophysiological characteristics, and involved in vasoregulatory functions, mitosis and cell cycle progression, apoptosis regulation, fatty acid biosynthesis, and endoplasmic reticulum stress-response. The role of these genes in the context of preeclampsia and EC physiological characteristics is discussed later.

\section{Genes Involved in Vasoregulatory Functions, Free Radical Production, and Angiogenesis Are Altered by the Preeclamptic Plasma}

Several genes identified as modified by the preeclamptic plasma are known to directly modify the properties of the endothelial vessels and, thus, are able to promote hypertension. Among those, EDNI, APLN, and CBS were significantly modified. EDN1, encoding ET-1, was the most up-regulated gene in the HUVECs treated with preeclamptic plasma. ET-1, mainly produced by ECs, possesses potent vasoactive activity. It has been implicated in the pathophysiological characteristics of many cardiovascular diseases. ${ }^{23,24}$ Circulating levels of ET-1 are increased in the blood of preeclamptic women, and several factors released by the preeclamptic placenta (including sFlt1, inflammatory cytokines, and agonistic angiotensin II type-1 receptor autoantibodies) are known to induce ET-1 expression. These factors induce hypertension in animal models through the production of ET-1, strengthening the possibility that ET-1 may be a mediator in the genesis of PE syndrome secondary to anti-angiogenic factors released by the placenta.

Another up-regulated gene in our experiment is $A P L N$, encoding apelin, a biologically active peptide present in several isoforms that are agonists for the orphan $\mathrm{G}$-coupled receptor, APJ. In the cardiovascular system, apelin is present in both the endothelium and vascular smooth muscle 
cells. Acting on the endothelium, it releases NO, which mediates vasodilation, whereas acting directly on vascular smooth muscle cells, it causes vasoconstriction. ${ }^{25} \mathrm{~A}$ possible role of apelin in hypertension, initial stages of heart failure, and ischemic heart disease has been suggested. ${ }^{26}$ Apelin levels have previously been found increased in the placenta and plasma of preeclamptic women. ${ }^{27,28}$

Among genes involved in vasoregulatory functions and down-regulated in our experiment, we found $C B S$. This gene encodes the cystathionine- $\beta$-synthase, an enzyme catalyzing the first and rate-limiting step of the transsulfuration pathway resulting in the conversion of homocysteine to the cysteine precursor, cystathionine. CBS can also catalyze the condensation of cysteine with homocysteine to form cystathionine and hydrogen sulfide $\left(\mathrm{H}_{2} \mathrm{~S}\right)$. $\mathrm{H}_{2} \mathrm{~S}$ is known to induce vasorelaxation by opening ATPsensitive $\mathrm{K}$ channels in smooth muscle cells and upregulating VEGF. Furthermore, $\mathrm{H}_{2} \mathrm{~S}$ has an antioxidant activity by directly scavenging NO and ROS. ${ }^{29}$ Endothelial dysfunction has been observed in Cbs-deficient mice, both homozygotes or heterozygotes. ${ }^{30,31}$ Isolated vessels from these animals display reduced dilatory response to endothelium-dependent vasodilators (bradykinin, acetylcholine, and $\beta$-methacholine). CBS down-regulation has also been reported in the placental endothelium of earlyonset preeclampsias. ${ }^{32}$ Altogether, these data show that $C B S$ could play a significant role in vasoregulation, and its involvement in the endothelial dysfunction of preeclampsia seems plausible. In sum, the up-regulation of EDNl and $A P L N$ and the down-regulation of $C B S$ in our experiment are consistent with their role in vasoregulatory functions and their known implication in the preeclamptic syndrome.

In relation to free radical production, and their deleterious effects in the context of preeclampsia, we found significant up-regulation of NOX4. This gene encodes an NADPH oxidase isoform. In ECs, NOX4 has been identified as a major source of ROS. ${ }^{33,34}$ Excessive ROS production has been convincingly implicated in vascular pathological conditions. Some studies indicate that NOX4 up-regulation activates ECs, arrests proliferation, and causes apoptotic and necrotic death. ${ }^{35}$ However, NOX4 overexpression promoted EC proliferation and inhibited apoptosis, whereas NOX4 silencing or expression of a dominant-negative form of NOX4 impaired EC proliferation. ${ }^{36}$ Further studies are needed to resolve these conflicting observations. Notwithstanding, it is likely that increased expression of NOX4 in ECs would lead to increased ROS production. ROS will activate various reduction-oxidation-sensitive kinases, such as Akt, Src, and mitogen-activated protein kinase, as well as transcription factors, including NF- $\kappa \beta, \mathrm{AP}-1, \mathrm{p} 53$, Ets, and hypoxia-inducible factor- 1 , thereby increasing reductionoxidation-sensitive gene expression, regulating growth, apoptosis regulation, migration, angiogenesis, permeability, and inflammation. ${ }^{34} \mathrm{~A}$ recent study has demonstrated that, through ROS production, NOX4 mediates the expression of plasminogen activator inhibitor-1 (PAI-1) via the p38 mitogen-activated protein kinase pathway in cultured human ECs. ${ }^{37}$ In this way, NOX4 could contribute to the procoagulant status observed in preeclampsia. By using entanercept, we show herein that $N O X 4$ transcriptional induction in ECs exposed to preeclamptic plasma is TNF- $\alpha$ dependent, whereas TNF- $\alpha$ levels are increased in preeclamptic plasma. Our results suggest, therefore, that inhibition of NOX4 transcription or activity could be a target for therapeutic approaches.

Another way of modifying the access of oxygen to the tissue, in addition to vasoconstriction/vasodilation, is the building of the vascular network. To this respect, we found herein that the gene encoding the vascular endothelial growth factor A (VEGFA), an important actor of endothelial proliferation, migration, permeability, survival, and vasodilation, is reduced in the HUVECs treated with preeclamptic plasma. In PE, the amount of bioavailable VEGF is decreased because the ischemic placenta releases sFLt1 into the maternal circulation. sFLt1 binds free VEGF and makes it unavailable for signaling via membrane-bound receptors. Endothelialderived VEGFA could play an essential role in maintaining endothelial homeostasis by regulating key vascular proteins, such as vascular endothelial growth factor receptor-2, tyrosine kinase with immunoglobulin and EGF homology domains-2, and vascular endothelial cadherin. ${ }^{38,39}$ Our results suggest that, in preeclampsia, the ECs might be confronted with a double lack of bioavailable VEGFA through the loss of paracrine and autocrine VEGFA signaling.

\section{Cell Proliferation versus Apoptosis in ECs Exposed to Preeclamptic Plasma}

Several up-regulated genes encode proteins that drive cell proliferation, suggesting that the preeclamptic plasma could be enriched in growth factors compared with normal pregnant plasma. This is consistent with other studies that have reported that preeclamptic plasma stimulates EC proliferation. ${ }^{40}$ Several factors present in the preeclamptic plasma at increased concentrations could be responsible for this effect: VEGF, ET-1, and oxidized low-density lipoprotein. In addition, increased ROS production subsequent to NOX4 up-regulation could also increase the expression of genes involved in EC growth and cell cycle progression, as previously mentioned. Consistently, a recent study comparing the transcriptome of peripheral blood mononuclear cells from preeclamptic and normal pregnant women found that many of the up-regulated genes in the preeclamptic peripheral blood mononuclear cells are involved in mitosis and cell cycle progression. ${ }^{41}$ Strikingly, several genes upregulated in this study are also found up-regulated in our experiment, including $C C N B 1, C C N B 2, C D C 20, C D C A 8$, $N E K 2$, and $C A S C 5$. Although proliferation is favored, antiapoptotic genes were consistently up-regulated in the HUVECs treated with preeclamptic plasma, such as BCL2A1, $B I R C 5$, and ID3. BCL2AI encodes a member of the BCL-2 protein family acting as an anti-apoptotic regulator ${ }^{42,43}$ 
capable of blocking caspase activation and whose expression has already been found up-regulated in the placenta of severe preeclampsias. ${ }^{44}$ BIRC5 encodes the baculoviral IAP repeatcontaining protein (also designated as survivin) and functions as a pivotal regulator of programmed cell death and mitosis. It interacts with the products of several genes found upregulated in our study, such as $C D C A 8, C D C 20, C C N B 1$, and $C C N B 2 . I D 3$ is a member of the basic helix-loop-helix family implicated in the pathobiological characteristics of vascular diseases of rodents, pigs, and humans. ${ }^{45-47}$ The increase in the expression of anti-apoptotic genes (such as BCL2A1, BIRC5, and ID3) and the concomitant downregulation of pro-apoptotic genes (such as IGFBP3), the expression of which is modified in the placenta and in the plasma of preeclamptic women,${ }^{48}$ DDIT3 or $C H A C 1$ ) could be an adaptive response to plasma factors (inflammatory cytokines and anti-angiogenic factors) that might trigger stress-challenging cell survival. Regulation of the apoptosis pathway by the preeclamptic plasma is also substantiated by the down-regulation of the pro-apoptotic branch of the UPR pathway. Indeed, our transcriptome analysis shows downregulation of the genes ATF4, CEBPB, CHAC1, TRIB3, $X B P-1$, and DDIT4 on exposure of the HUVECs to preeclamptic plasma. The UPR is activated in response to an overload of misfolded proteins in the ER. Stress sensors in the ER, such as ATF6, initiate signals on the cytosolic face of the ER to reduce protein synthesis, promote protein folding, and increase the degradation of misfolded proteins. Failure of this response to alleviate protein misfolding stress leads to late expression of proteins, such as DDIT3 (also designated as CHOP-10) or CHAC1, culminating in cell death. ${ }^{49}$ ER stress and UPR pathways have strong links to major inflammatory and stress signaling networks, including the activation of the JNK-AP1 and NF- $\kappa \mathrm{B}-\mathrm{IKK}$ pathways, as well as production of ROS and NO. ${ }^{50-52}$ In addition, the chaperone, HSPA5(BiP), which was up-regulated in the present study, has been proposed as a master regulator of the anti-apoptotic UPR signaling network. ${ }^{22}$ Increased expression of $\mathrm{HSPA5}(\mathrm{BiP})$ is induced by several factors, including elevated levels of ROS and intracellular homocysteine. ${ }^{53,54}$ Homocysteine-induced ER stress results in the induction of SREBP-dependent genes involved in the biosynthesis and uptake of cholesterol and triglycerides and leads to the accumulation of cholesterol in cultured HUVECs. ${ }^{55}$ We show herein that HUVECs exposed to the preeclamptic plasma up-regulate insulin-induced gene 1(INSIG1), a key component of the sterol regulatory element binding protein (SREBP-mediated regulation of cholesterol biosynthesis). ${ }^{56}$ INSIG1 binds to the sterol-sensing domain of SREBP cleavage-activating protein and retains the sterol-sensing domain of SREBP cleavage-activating protein/SREBP complex in the ER, preventing the translocation of the N-terminal domain of SREBP into the nucleus. This blocks SREBP from acting as a transcription factor for the genes involved in lipids and cholesterol biosynthesis (including INSIG1). A series of studies have demonstrated that EC inflammatory activation by oxidized phospholipids depletes cholesterol and activates SREBP nuclear translocation, with a concomitant increase in INSIGI mRNA levels. ${ }^{57}$ Increased circulating levels of triglycerides, low-density lipoproteins, and lipid peroxides have been found in the plasma of preeclamptic women. ${ }^{58,59}$ In addition to INSIGI, several other genes involved in fatty acid biosynthesis were found to be up-regulated in our study, including HMGCS1 and FASN, which are both targets of SREBP.

In sum, the modifications detected in HUVECs treated with preeclamptic plasma are coherent with what is known about endothelial dysfunction in preeclampsia. Deregulation of genes encoding vasoregulatory functions (EDN1, APLN, and $C B S$ ) can be linked to hypertension resulting from vasoconstriction. The concomitant up-regulation of genes encoding anti-apoptotic effectors and down-regulation of pro-apoptotic factors (including those involved in ER stress control) could be an adaptive response to plasma factors (ie, inflammatory cytokines and anti-angiogenic factors), which might trigger stress-challenging cell survival.

\section{Is JDP2 a Band Master of Endothelial Stress in Preeclampsia?}

One of the most striking findings of our analysis was the discovery that many of the modified genes contain AP-1 binding sites in their promoters. This correlates with the fact that JDP2 was one of the most down-regulated genes in the HUVECs treated with preeclamptic plasma, thus suggesting, for the first time to our knowledge, an involvement of this regulation cascade in endothelial defects in preeclampsia. $J D P 2$ encodes JDP2, a member of the AP-1 family implicated in many cellular processes, including carcinogenesis, cell differentiation, and cell proliferation. JDP2 is an 18.7$\mathrm{kDa}$ protein able to homodimerize, or heterodimerize, with other AP-1 members, such as c-Jun, JunB, JunD, DDIT-3 (CHOP-10), ATF2, and a member of the C/EBP family, $\mathrm{C} / \mathrm{EBP} \gamma$. JDP2 acts as a repressor of AP-1, cAMP-response element, and TPA-responsive element-dependent transcription. ${ }^{60,61}$ Although JDP2 acts generally as a repressor, it has been reported that, depending on the context and cell type, it can alternatively act as a transcriptional activator. ${ }^{62,63}$

In the present experiment, it was tempting to speculate that the up-regulation of several genes could result, at least in part, from the down-regulation of $J D P 2$. We tested this hypothesis by inhibiting JDP2 expression in the HUVECs using a JDP2 siRNA, followed by the analysis of the expression of a subset of genes containing AP-1 sites in their promoters and up-regulated by the exposure to preeclamptic plasma. $J D P 2$ silencing resulted in the upregulation of one gene (BCL2A1) of 16 genes found upregulated by preeclamptic plasma (and containing AP-1 sites in their promoter regions). JDP2 siRNA inhibition also leads to the down-regulation of IGFBP3 and VEGFA, two genes that are down-regulated in the HUVECs exposed to preeclamptic plasma. Thus, down-regulation of JDP2 by 
the preeclamptic plasma could directly explain at least the transcriptional modification of $B C L 2 A 1, I G F B P 3$, and $V E G F A$. Concerning the other genes, it is probable that the up-regulation of these genes requires the down-regulation of $J D P 2$ and the activation or down-regulation of other cofactors. Likely, the activity of such cofactors could be dependent on signals that can be provided by the preeclamptic plasma but not by the normal pregnancy plasma that could adapt the cells by countering the effect of JDP2 repression. Nevertheless, the fact that the single inhibition of JDP2 modifies their expression argues in favor of a role of JDP2 in their regulation, at least in the context of preeclampsia.

In summary, the significant response of HUVECs after 24 hours of exposition to preeclamptic plasma may help to understand the effects of preeclampsia on ECs, and allow the identification of the starting point of putative cascades of gene deregulations, which might be the source of long-term endothelial disorders in the patients. The data generated by our study set a novel base for future studies aiming to elucidate the effects of preeclampsia circulating factors on the physiological characteristics of ECs.

\section{Acknowledgment}

We thank Dr. Catherine Farnarier (Hôpital de la Conception, Marseille, France) for performing the cytokine measurements in the plasma of the pregnant women used in this study.

\section{Supplemental Data}

Supplemental material for this article can be found at http://dx.doi.org/10.1016/j.ajpath.2013.08.020.

\section{References}

1. Steegers EA, von Dadelszen P, Duvekot JJ, Pijnenborg R: Preeclampsia. Lancet 2010, 376:631-644

2. James JL, Whitley GS, Cartwright JE: Pre-eclampsia: fitting together the placental, immune and cardiovascular pieces. J Pathol 2010, 221: 363-378

3. VanWijk MJ, Kublickiene K, Boer K, VanBavel E: Vascular function in preeclampsia. Cardiovasc Res 2000, 47:38-48

4. Gilbert JS, Ryan MJ, LaMarca BB, Sedeek M, Murphy SR, Granger JP: Pathophysiology of hypertension during preeclampsia: linking placental ischemia with endothelial dysfunction. Am J Physiol Heart Circ Physiol 2008, 294:H541-H550

5. Baker PN, Stranko CP, Davidge ST, Davies PS, Roberts JM: Mechanical stress eliminates the effects of plasma from patients with preeclampsia on endothelial cells. Am J Obstet Gynecol 1996, 174: 730-736

6. Taylor RN, Crombleholme WR, Friedman SA, Jones LA, Casal DC, Roberts JM: High plasma cellular fibronectin levels correlate with biochemical and clinical features of preeclampsia but cannot be attributed to hypertension alone. Am J Obstet Gynecol 1991, 165: 895-901
7. Baker PN, Davidge ST, Roberts JM: Plasma from women with preeclampsia increases endothelial cell nitric oxide production. Hypertension $1995,26: 244-248$

8. Endresen MJ, Morris JM, Nobrega AC, Buckley D, Linton EA, Redman CW: Serum from preeclamptic women induces vascular cell adhesion molecule-1 expression on human endothelial cells in vitro: a possible role of increased circulating levels of free fatty acids. Am J Obstet Gynecol 1998, 179:665-670

9. Hayman R, Brockelsby J, Kenny L, Baker P: Preeclampsia: the endothelium, circulating factor(s) and vascular endothelial growth factor. J Soc Gynecol Investig 1999, 6:3-10

10. Matsubara K, Matsubara Y, Hyodo S, Katayama T, Ito M: Role of nitric oxide and reactive oxygen species in the pathogenesis of preeclampsia. J Obstet Gynaecol Res 2010, 36:239-247

11. Taylor RN, de Groot CJ, Cho YK, Lim KH: Circulating factors as markers and mediators of endothelial cell dysfunction in preeclampsia. Semin Reprod Endocrinol 1998, 16:17-31

12. Baker PN, Krasnow J, Roberts JM, Yeo KT: Elevated serum levels of vascular endothelial growth factor in patients with preeclampsia. Obstet Gynecol 1995, 86:815-821

13. Davidge ST, Stranko CP, Roberts JM: Urine but not plasma nitric oxide metabolites are decreased in women with preeclampsia. Am J Obstet Gynecol 1996, 174:1008-1013

14. Sankaralingam S, Xu Y, Sawamura T, Davidge ST: Increased lectinlike oxidized low-density lipoprotein receptor-1 expression in the maternal vasculature of women with preeclampsia: role for peroxynitrite. Hypertension 2009, 53:270-277

15. Donker RB, Asgeirsdottir SA, Gerbens F, van Pampus MG, Kallenberg CG, te Meerman GJ, Aarnoudse JG, Molema G: Plasma factors in severe early-onset preeclampsia do not substantially alter endothelial gene expression in vitro. J Soc Gynecol Investig 2005, 12 : 98-106

16. Bian C, Zhao K, Tong GX, Zhu YL, Chen P: Immortalization of human umbilical vein endothelial cells with telomerase reverse transcriptase and simian virus 40 large $\mathrm{T}$ antigen. J Zhejiang Univ Sci B 2005, 6:631-636

17. Gavard J, Gutkind JS: VEGF controls endothelial-cell permeability by promoting the beta-arrestin-dependent endocytosis of VE-cadherin. Nat Cell Biol 2006, 8:1223-1234

18. Huang da W, Sherman BT, Lempicki RA: Systematic and integrative analysis of large gene lists using DAVID bioinformatics resources. Nat Protoc 2009, 4:44-57

19. Huang da W, Sherman BT, Lempicki RA: Bioinformatics enrichment tools: paths toward the comprehensive functional analysis of large gene lists. Nucleic Acids Res 2009, 37:1-13

20. Pan J, Nakade K, Huang YC, Zhu ZW, Masuzaki S, Hasegawa H, Murata T, Yoshiki A, Yamaguchi N, Lee CH, Yang WC, Tsai EM, Obata Y, Yokoyama KK: Suppression of cell-cycle progression by Jun dimerization protein-2 (JDP2) involves downregulation of cyclinA2. Oncogene 2010, 29:6245-6256

21. Hasnain SZ, Lourie R, Das I, Chen AC, McGuckin MA: The interplay between endoplasmic reticulum stress and inflammation. Immunol Cell Biol 2012, 90:260-270

22. Bertolotti A, Zhang Y, Hendershot LM, Harding HP, Ron D: Dynamic interaction of $\mathrm{BiP}$ and ER stress transducers in the unfoldedprotein response. Nat Cell Biol 2000, 2:326-332

23. Schiffrin EL: Role of endothelin-1 in hypertension and vascular disease. Am J Hypertens 2001, 14:83S-89S

24. George EM, Palei AC, Granger JP: Endothelin as a final common pathway in the pathophysiology of preeclampsia: therapeutic implications. Curr Opin Nephrol Hypertens 2012, 21:157-162

25. Barnes G, Japp AG, Newby DE: Translational promise of the apelin-APJ system. Heart 2010, 96:1011-1016

26. Quazi R, Palaniswamy C, Frishman WH: The emerging role of apelin in cardiovascular disease and health. Cardiol Rev 2009, 17:283-286

27. Cobellis L, De Falco M, Mastrogiacomo A, Giraldi D, Dattilo D, Scaffa C, Colacurci N, De Luca A: Modulation of apelin and APJ 
receptor in normal and preeclampsia-complicated placentas. Histol Histopathol 2007, 22:1-8

28. Simsek Y, Celik O, Yilmaz E, Karaer A, Dogan C, Aydin S, Ozer A: Serum levels of apelin, salusin-alpha, and salusin-beta in normal pregnancy and preeclampsia. J Matern Fetal Neonatal Med 2012, 25 : $1705-1708$

29. Szabo C: Hydrogen sulphide and its therapeutic potential. Nat Rev Drug Discov 2007, 6:917-935

30. Eberhardt RT, Forgione MA, Cap A, Leopold JA, Rudd MA, Trolliet M, Heydrick S, Stark R, Klings ES, Moldovan NI, Yaghoubi M, Goldschmidt-Clermont PJ, Farber HW, Cohen R, Loscalzo J: Endothelial dysfunction in a murine model of mild hyperhomocyst(e)inemia. J Clin Invest 2000, 106:483-491

31. Weiss N, Heydrick S, Zhang YY, Bierl C, Cap A, Loscalzo J: Cellular redox state and endothelial dysfunction in mildly hyperhomocysteinemic cystathionine beta-synthase-deficient mice. Arterioscler Thromb Vasc Biol 2002, 22:34-41

32. Holwerda KM, Bos EM, Rajakumar A, Ris-Stalpers C, van Pampus MG, Timmer A, Erwich JJ, Faas MM, van Goor H, Lely AT: Hydrogen sulfide producing enzymes in pregnancy and preeclampsia. Placenta 2012, 33:518-521

33. Bedard K, Krause KH: The NOX family of ROS-generating NADPH oxidases: physiology and pathophysiology. Physiol Rev 2007, 87: 245-313

34. Frey RS, Ushio-Fukai M, Malik AB: NADPH oxidase-dependent signaling in endothelial cells: role in physiology and pathophysiology. Antioxid Redox Signal 2009, 11:791-810

35. Lener B, Koziel R, Pircher H, Hutter E, Greussing R, HerndlerBrandstetter D, Hermann M, Unterluggauer H, Jansen-Durr P: The NADPH oxidase Nox4 restricts the replicative lifespan of human endothelial cells. Biochem J 2009, 423:363-374

36. Datla SR, Peshavariya H, Dusting GJ, Mahadev K, Goldstein BJ, Jiang F: Important role of Nox4 type NADPH oxidase in angiogenic responses in human microvascular endothelial cells in vitro. Arterioscler Thromb Vasc Biol 2007, 27:2319-2324

37. Jaulmes A, Sansilvestri-Morel P, Rolland-Valognes G, Bernhardt F, Gaertner R, Lockhart BP, Cordi A, Wierzbicki M, Rupin A, Verbeuren TJ: Nox4 mediates the expression of plasminogen activator inhibitor-1 via p38 MAPK pathway in cultured human endothelial cells. Thromb Res 2009, 124:439-446

38. E G, Cao Y, Bhattacharya S, Dutta S, Wang E, Mukhopadhyay D: Endogenous vascular endothelial growth factor-A (VEGF-A) maintains endothelial cell homeostasis by regulating VEGF receptor-2 transcription. J Biol Chem 2012, 287:3029-3041

39. Lee S, Chen TT, Barber CL, Jordan MC, Murdock J, Desai S, Ferrara N, Nagy A, Roos KP, Iruela-Arispe ML: Autocrine VEGF signaling is required for vascular homeostasis. Cell 2007, 130:691-703

40. Rowe J, Campbell S, Gallery ED: Plasma from preeclamptic women stimulates decidual endothelial cell growth and prostacyclin but not nitric oxide production: close correlation of prostacyclin and thromboxane production. J Soc Gynecol Investig 2001, 8:32-38

41. Rajakumar A, Chu T, Handley DE, Bunce KD, Burke B, Hubel CA, Jeyabalan A, Peters DG: Maternal gene expression profiling during pregnancy and preeclampsia in human peripheral blood mononuclear cells. Placenta 2011, 32:70-78

42. Karsan A, Yee E, Kaushansky K, Harlan JM: Cloning of human Bcl2 homologue: inflammatory cytokines induce human A1 in cultured endothelial cells. Blood 1996, 87:3089-3096

43. Vogler M: BCL2A1: the underdog in the BCL2 family. Cell Death Differ 2012, 19:67-74

44. Founds SA, Conley YP, Lyons-Weiler JF, Jeyabalan A, Hogge WA, Conrad KP: Altered global gene expression in first trimester placentas of women destined to develop preeclampsia. Placenta 2009, 30:15-24
45. Lasorella A, Uo T, Iavarone A: Id proteins at the cross-road of development and cancer. Oncogene 2001, 20:8326-8333

46. Benezra R, Rafii S, Lyden D: The Id proteins and angiogenesis. Oncogene 2001, 20:8334-8341

47. Zhao Q, Beck AJ, Vitale JM, Schneider JS, Gao S, Chang C, Elson G, Leibovich SJ, Park JY, Tian B, Nam HS, Fraidenraich D: Developmental ablation of Id1 and Id3 genes in the vasculature leads to postnatal cardiac phenotypes. Dev Biol 2011, 349:53-64

48. Cooley SM, Donnelly JC, Geary MP, Rodeck CH, Hindmarsh PC: Maternal insulin-like growth factors 1 and 2 (IGF-1, IGF-2) and IGF BP-3 and the hypertensive disorders of pregnancy. J Matern Fetal Neonatal Med 2010, 23:658-661

49. Rutkowski DT, Kaufman RJ: That which does not kill me makes me stronger: adapting to chronic ER stress. Trends Biochem Sci 2007 , 32:469-476

50. Hu P, Han Z, Couvillon AD, Kaufman RJ, Exton JH: Autocrine tumor necrosis factor alpha links endoplasmic reticulum stress to the membrane death receptor pathway through IRE1alpha-mediated NFkappaB activation and down-regulation of TRAF2 expression. Mol Cell Biol 2006, 26:3071-3084

51. Cullinan SB, Diehl JA: Coordination of ER and oxidative stress signaling: the PERK/Nrf2 signaling pathway. Int J Biochem Cell Biol 2006, 38:317-332

52. Gotoh T, Mori M: Nitric oxide and endoplasmic reticulum stress. Arterioscler Thromb Vasc Biol 2006, 26:1439-1446

53. Outinen PA, Sood SK, Pfeifer SI, Pamidi S, Podor TJ, Li J, Weitz JI, Austin RC: Homocysteine-induced endoplasmic reticulum stress and growth arrest leads to specific changes in gene expression in human vascular endothelial cells. Blood 1999, 94:959-967

54. Kokame K, Kato H, Miyata T: Homocysteine-respondent genes in vascular endothelial cells identified by differential display analysis, GRP78/BiP and novel genes. J Biol Chem 1996, 271:29659-29665

55. Werstuck GH, Lentz SR, Dayal S, Hossain GS, Sood SK, Shi YY, Zhou J, Maeda N, Krisans SK, Malinow MR, Austin RC: Homocysteine-induced endoplasmic reticulum stress causes dysregulation of the cholesterol and triglyceride biosynthetic pathways. J Clin Invest 2001, 107:1263-1273

56. Dong XY, Tang SQ: Insulin-induced gene: a new regulator in lipid metabolism. Peptides 2010, 31:2145-2150

57. Yeh M, Cole AL, Choi J, Liu Y, Tulchinsky D, Qiao JH, Fishbein MC, Dooley AN, Hovnanian T, Mouilleseaux K, Vora DK, Yang WP, Gargalovic P, Kirchgessner T, Shyy JY, Berliner JA: Role for sterol regulatory element-binding protein in activation of endothelial cells by phospholipid oxidation products. Circ Res 2004, 95:780-788

58. Hubel CA, Lyall F, Weissfeld L, Gandley RE, Roberts JM: Small low-density lipoproteins and vascular cell adhesion molecule- 1 are increased in association with hyperlipidemia in preeclampsia. Metabolism 1998, 47:1281-1288

59. Potter JM, Nestel PJ: The hyperlipidemia of pregnancy in normal and complicated pregnancies. Am J Obstet Gynecol 1979, 133:165-170

60. Aronheim A, Zandi E, Hennemann H, Elledge SJ, Karin M: Isolation of an AP-1 repressor by a novel method for detecting protein-protein interactions. Mol Cell Biol 1997, 17:3094-3102

61. Jin C, Ugai H, Song J, Murata T, Nili F, Sun K, Horikoshi M, Yokoyama KK: Identification of mouse Jun dimerization protein 2 as a novel repressor of ATF-2. FEBS Lett 2001, 489:34-41

62. Wardell SE, Boonyaratanakornkit V, Adelman JS, Aronheim A, Edwards DP: Jun dimerization protein 2 functions as a progesterone receptor N-terminal domain coactivator. Mol Cell Biol 2002, 22: $5451-5466$

63. Weidenfeld-Baranboim K, Bitton-Worms K, Aronheim A: TREdependent transcription activation by JDP2-CHOP10 association. Nucleic Acids Res 2008, 36:3608-3619 